\title{
A social work study on the effect of gender and marital status on job satisfaction
}

\author{
Mohammad Reza Iravani ${ }^{a^{*}}$, Seyyed Saeed Hosseini ${ }^{\mathrm{b}}$, Mostafa Rajabi ${ }^{\mathrm{c}}$, Akram Fakhri Fakhramini ${ }^{\mathrm{d}}$, \\ Shirin Mirhaj ${ }^{\mathrm{e}}$, and Mina Shirvani ${ }^{\mathrm{f}}$
}

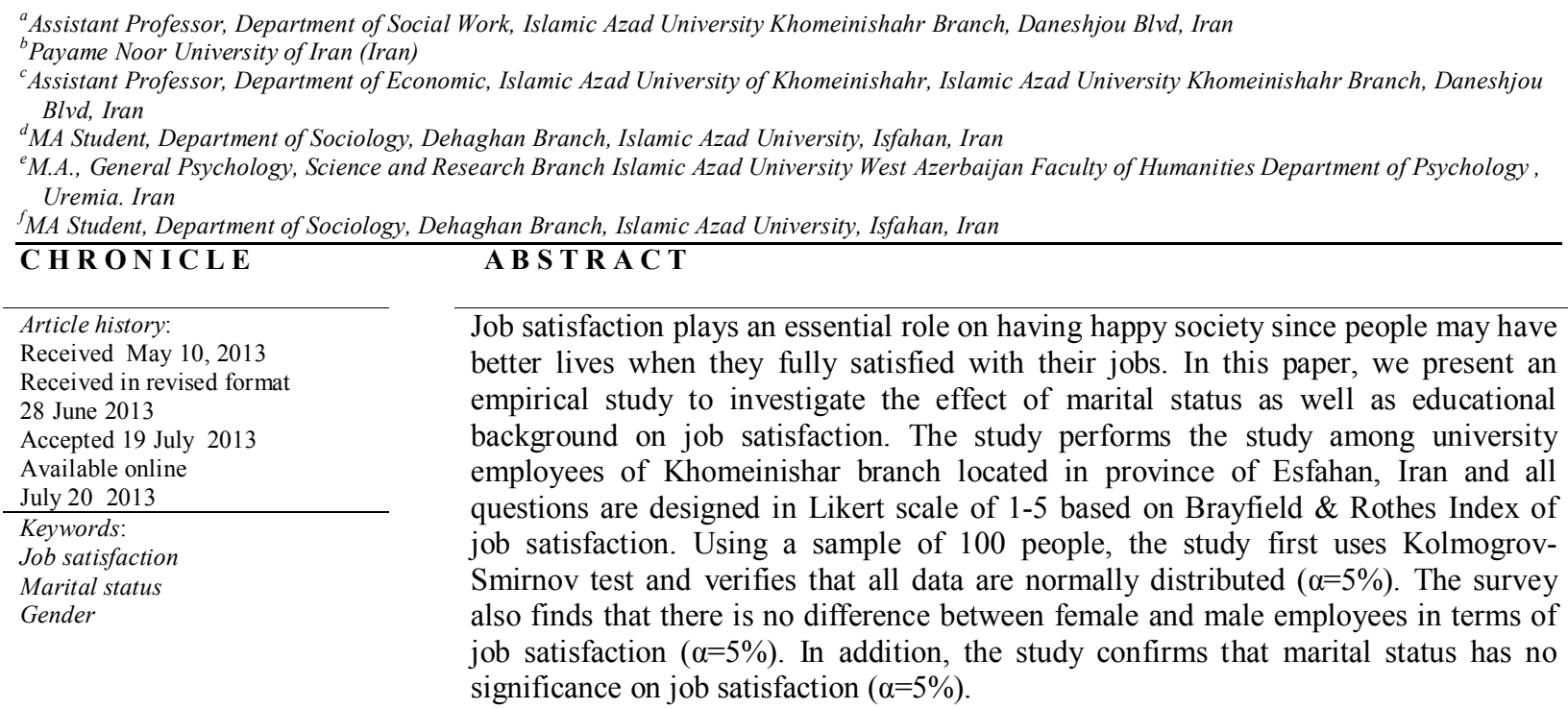

(C) 2013 Growing Science Ltd. All rights reserved.

\section{Introduction}

Job satisfaction is one of the most important assets of any firm and it plays important role in reaching organizational objectives. There are literally various studies on job satisfaction. Khodaei et al. (2013), for instance, presented an empirical study to investigate the impact of social capital on job satisfaction and citizenship behavior among 240 employees who worked for Allameh Tabataba'i University in Iran. They reported that social capital positively influences on both mentioned variables.

*Corresponding author. Tel: +989130758065

E-mail address: Iravani@iaukhsh.ac.ir (MR. Iravani) 
Boroumand and Abaadi (2013) did a survey to measure the impacts of five factors including work conditions, pay, promotion, supervisor and co-worker on job satisfaction among 130 employees who worked for one of Iranian transmission electricity in Iran. They presented a method to find desirable weights for each component of job satisfaction. Aminjafari et al. (2012) performed an empirical study based on the implementation of factor analysis to detect various factors influencing people to have more stress in a hydropower unit located in city of Esfahan, Iran. The results of a factor analysis demonstrated that among various factors, difficulty of working condition as well as work pressure were two most important factors increasing stress among employees.

Hanzaee et al. (2013) investigated the impact of employees' Emotional Intelligence (EI), Job Satisfaction (JS) and Organizational Citizenship Behavior (OCB) on Employee's Performance (EP) in Iranian hotel industry. They designed a questionnaire and distributed it among 225 employees who had a high interaction with customers in hotel industry. They confirmed all the proposed hypotheses of their survey except the one, which was associated with the relationship between OCB on EP. In other words, EI had positive impacts on JS, OCB and EP in Iranian hotel industry.

Baseri (2013) examined the level of job satisfaction of auditors of audit organizations in comparison to accountants in Business enterprise. They also tried to analyze the effective factors on job satisfaction in two groups to point to essential guidelines and decreased the job quit in this part of society and increased the efficiency of human resource, even very little. Results obtained from the study hypothesis indicated that range of dissatisfaction among auditors was more than accountants.

Iravani et al. (2012a) performed an empirical survey to measure the effect of stress among people with different gender and marital status in a hydropower unit located in city of Esfahan, Iran. The study performed the survey among all 81 people who were working for customer service section of this company and consisted of two parts, in the first part; they gathered all private information such as age, gender, education, job experience, etc. through seven important questions. In the second part of the survey, there were 66 questions, which included all the relevant factors impacting employees' stress. They implemented two Levin and t-student tests to find out whether gender or marital status had any meaningful influences on creating stress among people. The results indicated that gender had no meaningful effect on creating stress among employees who worked for this hydro plant except difficulty of job conditions. The other findings of this paper was that stress posed from management team had various impacts on employees with different marital status but there were no meaningful differences between married and single couples in terms of other factors posing stress such as unsuitable working conditions, fear of job stability or difficulty of job conditions.

Iravani et al. (2012b, 2012c), in other studies, performed an empirical study based on the implementation of ANOVA and LSD tests to measure the effect of stress among people with various job titles and ages in a hydropower unit located in city of Esfahan, Iran. The study performed the survey among all 81 people who were working for customer service section of this company and consisted of two parts, in the first part; they gathered all private information such as age, gender, education, job experience, etc. through seven important questions. In the second part of the survey, there were 66 questions, which included all the relevant factors impacting employees' stress. Cronbach alpha was calculated as 0.946 , which was well above the minimum acceptable level. The implementation of ANOVA and LSD tests disclosed that there were no meaning differences among people with different job titles but people in different age groups maintained different level of stress.

\section{The proposed study}

In this paper, we present an empirical study to investigate the effect of marital status as well as educational background on job satisfaction. The study performs the study among university employees of Khomeinishar branch located in province of Esfahan, Iran and all questions are 
designed in Likert scale of 1-5 based on Brayfield \& Rothes Index of job satisfaction (Brayfield \& Rothe, 1951). The questionnaire has been wiedly used by many researchers in the world and it has been recommended by many researchers. In this paper, authors presented an investigation on an attitude scale to give an index of job satisfaction by a combination of Thurstone and Likert scaling methods. The sample size is calculated as follows,

$n=\frac{N \times z_{\alpha / 2}^{2} \times p \times q}{\varepsilon^{2} \times(N-1)+z_{\alpha / 2}^{2} \times p \times q}$,

where $N$ is the population size, $p=1-q$ represents the yes/no categories, $z_{\alpha / 2}$ is CDF of normal distribution and finally $\varepsilon$ is the error term. Since we have $p=0.5, z_{\alpha / 2}=1.96$ and $N=800$, the number of sample size is calculated as $n=99$. The proposed study considers the following two hypotheses,

1. There is a relationship between gender and job satisfaction.

2. There is a relationship between marital status and job satisfaction.

In this study, we distrubuted 100 questionnares among randomly selected population. The next step is to verify whether the data are normally distributed or not. Table 1 shows details of our normality test using Kolmogrov-Smirnov test.

Table 1

The results of Kolmogrov-Smirnov test

\begin{tabular}{lcc}
\hline & Job satisfaction & Marital satisfaction \\
\hline Number & 100 & 100 \\
Mean & 9.72 & 10.46 \\
Standard deviation & 1.61 & 1.81 \\
Absolut deviation & 0.183 & 0.126 \\
Positive deviation & 0.183 & 0.124 \\
Negative deviation & -0.093 & -0.094 \\
Statistics & 1.36 & 0.908 \\
Two-side Sig. & 0.063 & 0.389 \\
\hline
\end{tabular}

The results of Table 1 indicates that we can reject the null hypothsis and conclude that the data are normally distributed $(\alpha=5 \%)$.

\section{The results}

In this section, we present details of our investgation on testing two hypotheses of this survey using tstudent test.

\subsection{The first hypothsis: The relationship between gender and job satsfaction}

The first hypothsis of this survey considers the relationship between gender and job satisfaction. Table 2 demonstrates the results of our survey.

Table 2

The summary of testing the relationship between gender and job satisfaction

\begin{tabular}{lrrrrr}
\hline Gender & Mean of job satisfaction & Standard deviation & T & df & Sig. \\
\hline Male & 9.36 & 1.86 & \multirow{2}{*}{0.326} & 99 & 0.721 \\
Female & 9.48 & 1.81 & & \multirow{2}{*}{9} & \\
\hline
\end{tabular}


As we can observe from the results of Table 2, t-student is not meaningful when the level of significance is five percent. Therefore, we can conclude that there is no meaningful relationship between gender and job satisfaction.

\subsection{The second hypothsis: The relationship between marital status and job satsfaction}

The second hypothsis of this survey considers the relationship between marital status and job satisfaction. Table 3 demonstrates the results of our survey.

\section{Table 3}

The summary of testing the relationship between marital status and job satisfaction

\begin{tabular}{lrrrrr}
\hline Marital status & Mean of job satisfaction & Standard deviation & T & df & Sig. \\
\hline Married & 9.61 & 1.94 & \multirow{2}{*}{0.246} & \multirow{2}{*}{99} & 0.811 \\
Single & 9.21 & 2.83 & & \\
\hline
\end{tabular}

As we can observe from the results of Table 3, t-student is not meaningful when the level of significance is five percent. Therefore, we can conclude that there is no meaningful relationship between marital status and job satisfaction.

\section{Conclusion}

In this paper, we have presented an empirical investigation to find the relationship between gender as well as marital status and job satisfaction. The proposed study has addopted a questionnaire and distributed among 100 regular employees of a private university in Iran. The results of our study have indicated that neither gender nor marital status had any meaningful effect on job satisfaction.

\section{References}

Aminjafari, B., Ghojavand, K., Iravani, G., Iravani, M \& Vakili, D. (2012). A social work study using factor analysis on detecting important factors creating stress: A case study of hydro-power employees. Management Science Letters, 2(5), 1761-1768.

Baseri, S. (2013). An investigation on of job satisfaction in accounting and auditing institutions of commercial companies. Management Science Letters, 3(2), 683-688.

Brayfield, A. H., \& Rothe, H. F. (1951). An index of job satisfaction. Journal of applied psychology, 35(5), 307.

Boroumand, Z \& Abaadi, M. (2013). An investigation on factors influencing job satisfaction: A case study of electricity distribution firm. Management Science Letters, 3(7), 1879-1884.

Hanzaee, K \& Mirvaisi, M. (2013). A survey on impact of emotional intelligence, organizational citizenship behaviors and job satisfaction on employees' performance in Iranian hotel industry. Management Science Letters, 3(5), 1395-1402.

Iravani, M., Iravani, G., Khorvash, M \& Mosavi, S. (2012a). A social work study on measuring the impact of gender and marital status on stress: A case study of hydro-power employees. Management Science Letters, 2(6), 2097-2102.

Iravani, A., Iravani, M., Iravani, G., Khorvash, M \& Mosavi, S. (2012b). A social work study on measuring the impact of age and job title on stress: A case study of hydro-power employees.Management Science Letters , 2(6), 2243-2248.

Iravani, G., Iravani, A., Jafari, E., Salimi, S \& Iravani, M. (2012c). A social work study on detecting organizational and job related factors creating stress: A case study of hydro power employees. Management Science Letters, 2(4), 1447-1454.

Khodaei, R., Valehzaghard, H \& Anvar, H. (2013). A study on the effect of social capital on job satisfaction and citizenship behaviour. Management Science Letters, 3(7), 1873-1878. 